\title{
Physiological, Biochemical and Psychological Markers of Strenuous Training-Induced Fatigue
}

\section{Abstract}

The purpose of the study was to investigate whether severe fatigue, possibly leading to overreaching, could be diagnosed at an early stage by a combination of parameters. Seven well-trained male subjects (age [mean $\pm \mathrm{SD}$ ]: $25.3 \pm 4.7 \mathrm{yr}$; body mass: $76 \pm 6.6 \mathrm{~kg} ; \mathrm{VO}_{2} \max : 61.1 \pm 7 \mathrm{ml} \cdot \mathrm{kg}^{-1} \cdot \mathrm{min}^{-1}$ ) increased their training load by doubling their training volume and increasing the intensity by $15 \%$ over a period of two weeks. Before and after this intensified training period subjects underwent a series of tests including a maximal incremental cycle ergometer test (Wmax) with continuous ventilatory measurements and blood lactate values, time trial, basal blood parameter tests (red and white blood profile), hormones [growth hormone $(\mathrm{GH})$, insulinlike growth factor 1(IGF-1), adreno-corticotropic hormone (ACTH), cortisol], neuro-endocrine stress test [short insulin tolerance test (SITT), combined anterior pituitary test (CAPT) and exercise], a shortened Profile of Mood State (POMS), the estimated rate of perceived exertion (RPE) and a cognitive reaction time test. The intensified training period resulted in a significant increase of the training load $(\mathrm{p}<0.01)$, training monotony $(\mathrm{p}<0.01)$ and training strain $(\mathrm{p}<0.01)$. The RPE during training increased significantly $(\mathrm{p}<0.01)$ during the intensified training period. Total mood score obtained from the POMS tended to in- crease $(p=0.06)$, reflecting an increase in worse mood state. A novel finding was that reaction times increased significantly, indicating that overreaching might adversely affect speed of information processing by the brain, especially for the most difficult conditions. After the intensified training period, neither changes in exercise-induced plasma hormone values, nor SITT values were observed. During the CAPT only cortisol showed a significant decrease after the intensified training period. Hemoglobin showed a significant decrease after the intensified training period whereas hematocrit, red blood cell count (RBC) and MCV tended to decrease. The intensified training had no effect on physical performance (Wmax or time trial), maximal blood lactate, maximal heart rate and white blood cell profile. The most sensitive parameters for detecting overreaching are reaction time performance (indicative for cognitive brain functioning), RPE and to a lesser extend the shortened POMS. This strongly suggests, that central fatigue precedes peripheral fatigue. All other systems,including the neuro-endocrine, are more robust and react most likely at a later stage in exhaustive training periods.

\section{Key words}

Overreaching $\cdot$ performance $\cdot$ POMS $\cdot$ training monitoring $\cdot$ hormones reaction time

Affiliation

${ }^{1}$ Department of Movement Sciences, Maastricht University, Maastricht, The Netherlands

2 Department of Human Biology, Maastricht University, Maastricht, The Netherlands

${ }^{3}$ Brain and Behavior Institute, Maastricht University - Nutrition and Toxicology Research Institute Maastricht (NUTRIM), Maastricht, The Netherlands

Correspondence

H. A. Keizer · Department of Movement Science - Maastricht University · P.O. Box 616 . 6200 MD Maastricht · The Netherlands · Phone: + 31433881397 · Fax: + 31433670972 . E-mail: Hans.keizer@bw.unimaas.nl

Accepted after revision: November 15, 2003 


\section{Introduction}

In order to improve performance, physical training requires an optimal balance between training load (intensity and volume) and recuperation $[28,33]$. Furthermore, social and psychological factors play a role in performance as well. In extremely well trained athletes, however, this is not always easy to accomplish. Most of the training regimens that maintain or augment performance are often highly demanding and therefore may easily lead to an imbalance in the load versus recovery time. Moreover, the increasing amount of international competitions put a heavy burden on social and psychological factors.

If a state of general imbalance continues for a prolonged period of time, it may eventually lead to overreaching and/or an overtraining syndrome $[18,21,28,32]$. The overtraining syndrome is complex and characterized by a wide variety of symptoms [41,54-56]. The most important symptom for a full blown overtraining syndrome is an inexplicable decrease in performance which holds on for months despite training reduction [28,32]. Since the complexity of the overtraining syndrome excludes proper medical intervention and overtrained athletes are for months unable to compete, prevention is mandatory.

From the very scanty literature dealing with a full blown overtraining syndrome it emerges that changes at the level of the central-nervous system, the neuro-endocrine system as well as at the peripheral level have occurred $[5,10,34,35,55]$. For example, insomnia with or without nocturnal sweating, mild to severe depression and other negative mental feelings are clear indications of the involvement of the central nervous and system [25, $40,46]$.

Evidence for derangements within the neuro-endocrine system was reported, among others, by Lehman et al., showing a diminished cortisol response to adreno-corticotropic hormone (ACTH) upon stimulation with the homologic hypothalamic-pituitary stressor corticotropin releasing hormone (CRH) [35]. Contradictory results are presented by Barron et al. (1985) who reported decreased ACTH levels in overtrained athletes stimulated with a heterologic stressor (insulin-induced hypoglycemia) [5]. However, Barron et al. reported data from only four overtrained athletes and unfortunately no other studies have confirmed these results.

Derangements of peripheral origin are often manifested as an increased susceptibility to infections caused by a malfunction of the immune system $[16,20,36]$. Also derangements of the hematological system have been reported $[37,49]$.

It is now generally accepted that a state of overreaching (defined as an unexpected and inexplicable stagnation in performance, which holds on for 3-6 weeks, despite training reduction [32]) precedes the full blown overtraining syndrome. One of the most important features of overreaching is the increased fatigability and delayed recovery during and after a normal training load [28]. Although several attempts have been made to diagnose the overreaching/overtraining syndrome, general diagnostic parameters have not yet been found $[3,56]$. Although there is circumstantial evidence that the physiological response to a imbal- ance in training load and adequate recovery varies between individuals [58], most studies performed have not taken into account the complex interplay between all the parameters characterizing the different systems involved.

Therefore, the present study investigates central and peripheral physiological, endocrine and psychological responses to a brief period ( 2 weeks) of very demanding exercise training causing a state of severe fatigue. Our goal was to attain a state of overreaching in seven well-trained cyclists by a substantial increase in training load by doubling the training volume and increasing the training intensity by $15 \%$.

The main aim of the present study was to establish whether early overreaching could be diagnosed by a combination of a selected number of parameters, representative for the status of the central nervous, neuro-endocrine and peripheral systems.

\section{Materials and Methods}

\section{Subjects}

Seven healthy, well-trained male cyclists with a mean ( \pm SD), height, body mass and $\mathrm{VO}_{2} \max$ of $25.3 \pm 4.7 \mathrm{yr}, 184.6 \pm 2.7 \mathrm{~cm}$, $76 \pm 6.6 \mathrm{~kg}$ and $61.1 \pm 7 \mathrm{ml} \cdot \mathrm{kg}^{-1} \cdot \mathrm{min}^{-1}$, respectively, volunteered to participate in this study after giving written informed consent. The Medical Ethical Committee of the Maastricht University previously approved the project. All subjects completed a medical checklist. None of them was taking any medication known to affect the hypothalamic-pituitary-adrenal (HPA) axis. Additionally, a group of seven healthy, well-trained, age-matched cyclists were included and served as a control group for the cognitive speed test measurements. These subjects maintained a normal non-exhaustive training regimen.

\section{Measurements}

The subjects underwent a two-week intensified training period, preceded by a two-week pre-intervention period. In these weeks, the subjects performed a normal training program. Immediately before and directly after the two-week intensified training period, they underwent a series of tests consisting of anthropometric measurements, a cognitive speed test, operationalized by means of the finger-precuing reaction time task [39], an incremental exercise ergometer test, a performance test (time trial), a short insulin tolerance test (SITT) and a combined anterior pituitary (CAPT) test. A shortened profile of mood state (POMS) [12,13] questionnaire was administered to each subject on a daily basis. The sequence of testing and training is illustrated in Fig. 1. For each subject, all testing was done at the same time of the day. Subjects had to refrain from training for at least 24 hours before each time point for data collection. Consequently, they did not train on days 12,13 (i.e. after the pre-intensified training period), 28 and 29. Finally, the subjects were asked to consume the same diet for the last 48 hours before they reported to the laboratory.

\section{Anthropometric parameters}

Body height, body mass and percentage body fat were measured prior to and at the end of the intensified training period (Table $\mathbf{1}$ ). Percentage body fat was calculated using the skin fold method, according to Durnin and Womersley [14]. 


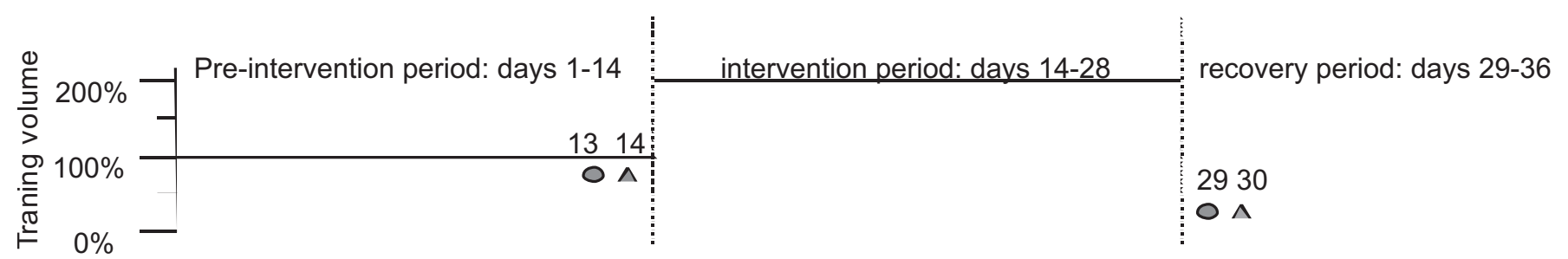

Fig. 1 Schematic representation of the study design. The study started with a two week monitor period (pre-intervention period), followed by a two week intervention period wherein training load was $100 \%$ increased. Anthropometric performance and hematological var- iables were measured before and after the intervention period. Mood state was measured daily throughout the pre- and intervention period. Circle; anthropometric-, hematological- and incremental exercise test. Triangle: time trial test.

Table 1 Anthropometric, performance and hematological variables before and after the two weeks intensified training

\begin{tabular}{|c|c|c|c|c|}
\hline Parameter & $\begin{array}{l}\text { Pre-intervention } \\
\text { mean SD }\end{array}$ & $\begin{array}{l}\text { Post-intervention } \\
\text { mean SD }\end{array}$ & \% difference & p value \\
\hline Training volume (min/week) & $420 \pm 204$ & $870 \pm 295$ & 107.14 & $<0.01$ \\
\hline \multicolumn{5}{|l|}{ Anthropometry } \\
\hline - Body mass $(\mathrm{kg})$ & $76 \pm 6.6$ & $75.8 \pm 6$ & -0.26 & 0.66 \\
\hline - Body fat (\%) & $13.3 \pm 2.5$ & $12.9 \pm 2.5$ & -3.01 & 0.32 \\
\hline \multicolumn{5}{|l|}{ Performance test } \\
\hline - Time trial (s) & $1817 \pm 107$ & $1847 \pm 161$ & 1.65 & 0.86 \\
\hline - Maximal workload (Watt) & $325 \pm 5.7$ & $337 \pm 5.5$ & 3.69 & 0.08 \\
\hline - Maximal oxygen uptake $(\mathrm{ml} \cdot \mathrm{kg} \cdot \mathrm{min})$ & $58.3 \pm 7.8$ & $58.7 \pm 6.6$ & 0.69 & 0.86 \\
\hline - Peak blood lactate (mmol/l) & $11.5 \pm 3.1$ & $11.2 \pm 2.4$ & -2.61 & 0.86 \\
\hline \multicolumn{5}{|l|}{ Blood profile } \\
\hline$-H b(\mathrm{mmol} / \mathrm{l})$ & $8.86 \pm 0.36$ & $8.46 \pm 0.31$ & -4.51 & $<0.01$ \\
\hline - Hct (\%) & $0.43 \pm 0.03$ & $0.41 \pm 0.03$ & -4.65 & 0.25 \\
\hline$-R B C(p l)$ & $4.67 \pm 0.24$ & $4.54 \pm 0.28$ & -2.78 & 0.2 \\
\hline - MCV (fl) & $92.76 \pm 6.31$ & $89.5 \pm 5.03$ & -3.51 & 0.33 \\
\hline$-W B C$ & $5.3 \pm 1.33$ & $5.61 \pm 1.68$ & 5.85 & 0.79 \\
\hline - Leucocytes & $1.98 \pm 0.59$ & $1.94 \pm 0.6$ & -2.02 & 0.14 \\
\hline - Monocytes & $0.98 \pm 0.82$ & $0.33 \pm 0.08$ & -66.33 & 0.1 \\
\hline - Granulocytes & $2.32 \pm 0.81$ & $2.73 \pm 0.67$ & 17.67 & 0.48 \\
\hline
\end{tabular}

Values are mean $\pm S D$, significance was accepted at $p<0.05$ level

\section{Cognitive speed test}

\section{Apparatus and stimuli}

Stimuli were presented on a standard video display monitor controlled by an IBM ${ }^{\circledR}$-AT computer. Responses were made by pressing one of four keys of the keyboard (the two left-most and two right-most keys on the bottom row of the keyboard operated by the index and middle fingers of both hands). Viewing distance was held constant at about $50 \mathrm{~cm}$. The computer was housed in a normally lit room, and was used to control the presentations of the stimulus displays and to record response latencies and accuracies, as described earlier [1]. Stimuli were plus $(+)$ signs presented in the standard character set of the computer. The stimulus display consisted of a warning signal, a cue signal, and a target signal, with the entire display centered on the viewing monitor. The warning signal was a row of four plus signs (Fig. 2). After a delay of $750 \mathrm{~ms}$, the cue signal appeared immediately below the warning signal. The cue consisted of plus signs either in all four positions indicated by the warning signal (uncued condition) or in only two of the four possible positions (hand-cued, fin- ger-cued, neither-cued conditions). We distinguished four precue or preparation conditions. In the hand-cued condition, the precue specified two fingers on the same hand (e.g., the left-middle and left-index fingers). In the finger-cued condition, the precue specified the same finger on different hands (e.g., the left-index and right-index fingers). In the neither-cued condition, the precue specified different fingers on different hands (e.g., the left-middle and right-index fingers). Also, an uncued condition was included. Here, the "precue" provides no advance information (it contains plus signs in all four possible stimulus locations), and thus precludes selective preparation of any combination of two finger responses. This condition is a control condition. After a variable (preparation) interval (i.e., 100 or $1000 \mathrm{~ms}$ ) the target signal (one single plus sign) appeared immediately below the cue row, in a position always indicated by the cue. The subject's task was to respond as quickly as possible to the position in which the target signal occurred by pressing the appropriate response key. Reaction time (RT) was defined as the time between target onset and key-press response. Target signal and response 


\section{Uncued}

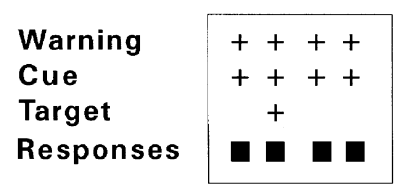

Hand-Cued
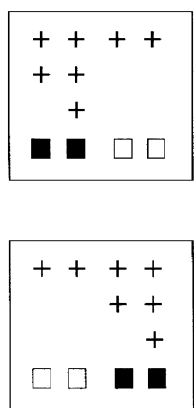

Finger-Cued
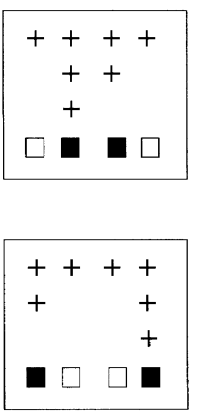

Neither-Cued
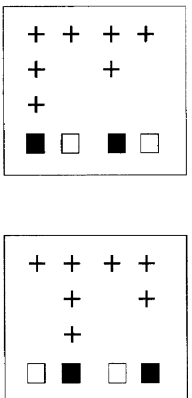

Fig. 2 Schematic representation of the finger precuing reaction time task and the four preparation conditions. The black squares indicate the possible responses indicated by the cue, and thus reflect the number and type of prepared responses. Note that in all conditions only one response was actually required, namely the finger response indicated by the single target stimulus. key were mapped onto each other in a spatially compatible manner, such that a target appearing in the left-most position was to be responded to with the left middle finger pressing the leftmost response key, etc. An inter-trial interval of $1 \mathrm{~s}$ separated the response in a trial from the start of the next trial.

\section{Procedures}

Two preparation intervals were used (100 and $1000 \mathrm{~ms}$ ). Each subject received a block of 80 trials for each preparation interval. A rest period of $3 \mathrm{~min}$ was provided between blocks. Within a block of 80 trials, there were 20 trials for each of the four cue conditions. The order of these cuing conditions within a block of 80 trials was random. Twenty-five practice trials preceded each block of 80 test trials.

Participants were informed regarding the nature of the task and were explicitly told to take advantage of the cue stimulus. They were instructed to react as quickly as possible to the target stimulus by pressing the correct response key. Error feedback was provided on individual trials.

\section{Profile of mood state (POMS)}

A shortened version of the POMS questionnaire [12,13] was administered daily during the entire study in order to quantify the influence of intensified training on mood state. The shortened POMS assessed tension, depression, anger, vigor and fatigue. The total mood score was measured by summing the scores of the negative moods (tension, depression, anger and fatigue) and subtracting the vigor score. From this daily score a weekly average score was calculated. The higher this mood score, the worse the mood state. Furthermore the average weekly score of each individual item was analyzed.

\section{Performance tests}

\section{Incremental exercise test}

After insertion of a Teflon catheter in an antecubital vein, the subject rested in supine position for 20 minutes. Blood samples for lactate, adrenocorticotropic hormone (ACTH), cortisol, thyroid-stimulating hormone (TSH), and growth hormone $\mathrm{GH}$ were drawn at rest and immediately after the termination of the test. From the sample obtained before the test a red [24], hematocrit (Htc), red blood cell count (RBC), Mean Corpuscular Volume (MCV) and white blood cell profile (white blood cell count [WBC], leucocytes, monocytes granulocytes) was analyzed as well. The subjects had to complete the incremental exercise test on an electro-magnetically braked cycle ergometer (Lode Excali- bur Sport ${ }^{\circledR}$, Lode, The Netherlands) that was calibrated at rpm values between 70 and $100 \mathrm{rpm}$. The initial workload of the maximal workload test was set at $1 \mathrm{~W} \cdot \mathrm{kg}^{-1}$ body weight (BW), and increased by $0.5 \mathrm{~W} \cdot \mathrm{kg}^{-1}$ BW every three minutes until volitional exhaustion. The test was stopped when the subject was not able to maintain a pedalling rate of at least $60 \mathrm{rpm}$, despite strong encouragement by the researchers. Throughout the test, gas exchange (Oxycon beta ${ }^{\circledR}$, Jaeger, Würzburg, Germany) and heart rate (Polar ${ }^{\circledR}$, Kempele, Finland) were measured continuously. $\mathrm{VO}_{2}$ max was calculated as the average of the last 30 seconds. The test was considered to be maximal when at least three of the following criteria was met: heart rate $>185$, blood lactate $>10$, respiratory exchange ratio $>1.15$, respiratory rate $>45$, no further increase in $\mathrm{VO}_{2}$, despite increase in workload. The maximal workload (Wmax) was defined as the last completed work load step (Watts) plus the time (in seconds) the subject could sustain the final work rate divided by (180) multiplied by the increase in workload (in Watts) after the last completed step [29].

\section{Time trial}

To obtain an additional reproducible measure of performance, a simulated time trial was used [26]. The measure of performance was the time required to complete an amount of work determined by the following formula:

Target amount of work $(\mathrm{J})=75 \% \mathrm{Wmax} \cdot 1800 \mathrm{~s}$

During this test the subjects were not informed about their workload, pedaling rate, heart rate or elapsed time.

\section{Hormone provocation tests Short insulin tolerance test (SITT)}

In order to study the endocrine response during a hypoglycemic challenge test, the SITT was used $[2,8]$. The subjects reported to the laboratory after an overnight fast. They had to refrain from physical exercise 24 hours preceding the SITT. To obtain arterialized blood samples the forearm and hand were held in a heated air box set at $60^{\circ} \mathrm{C}$. In the contra-lateral arm an intravenous catheter was inserted in the antecubital vein for the injection of insulin. After 30 minutes of rest, 0.04 units $\cdot \mathrm{kg}^{-1} \mathrm{BW}$ short acting insulin (Human Actrapid Insulin ${ }^{\circledR}$, Novo Nordisk A/S, Denmark) was injected. Blood samples for adrenocorticotropic hormone (ACTH), cortisol, thyroid-stimulating hormone (TSH) and growth hormone (GH) were drawn just before, and 10, 20, 40, 60, 80 and 100 min after the insulin injection. Blood glucose was measured every 2.5 minutes during the first $40 \mathrm{~min}$ and every $10 \mathrm{~min}$ there- 
after. If blood glucose levels dropped below $2.0 \mathrm{mmol} / \mathrm{l}$ or if other symptoms of severe hypoglycemia occurred, the test was terminated and a bolus injection of $20 \mathrm{ml} 20 \%$ glucose solution in saline was administered.

\section{Combined anterior pituitary test (CAPT)}

On a separate day, the athletes reported to the laboratory at 8.30 a.m. after an overnight fast. Because the SITT does not discriminate between hypothalamic and pituitary dysfunction, the CAPT was used to assess pituitary function. After insertion of a catheter in the antecubital veins of both arms, the athlete was seated for 2 hours. Ten minutes after the insertion the catheters, a bolus injection with a physiological dose of releasing hormones (33.3 $\mu \mathrm{g}$ corticotropin-releasing hormone [CRH], $17.0 \mu \mathrm{g}$ gonadotropin-releasing hormone [GhRH] (somatorelineacetaat) and $0.066 \mathrm{mg}$ thyrotropin-releasing hormone [TRH]) in $10 \mathrm{ml}$ saline was given. Blood $(10 \mathrm{ml})$ for analysis of ACTH, cortisol, TSH and GH was sampled from the other catheter just before the bolus injection, and 10, 20, 40, 60, 80 and 100 min after the injection.

\section{Blood sample processing and analysis}

Blood samples $(1 \mathrm{ml})$ for lactate were collected in heparinized tubes, centrifuged at $5000 \mathrm{rpm}$ at $4{ }^{\circ} \mathrm{C}$. and the plasma frozen at $-20^{\circ} \mathrm{C}$ until analyzed on a semi-automatic analyser (Cobas FARA $^{\circledR}$, La Roche, Basel, Switzerland). Red and white blood cell samples ( $4 \mathrm{ml}$ ) were collected in EDTA tubes and analysed immediately (Coulter MD18 ${ }^{\circledR}$, Miami, USA). Four ml of blood were collected for cortisol, TSH, GH and IGF-1 analysis in serum tubes, and centrifuged at $5000 \mathrm{rpm}$ at $4{ }^{\circ} \mathrm{C}$ after clotting. The resulting plasma was collected and stored at $-20^{\circ} \mathrm{C}$. Samples for ACTH were collected in pre-cooled EDTA tubes and immediately centrifuged at $5000 \mathrm{rpm}$ at $4^{\circ} \mathrm{C}$. Plasma for ACTH was stored at $-20^{\circ} \mathrm{C}$. All samples from one subject were analyzed in one assay to avoid interassay variability. Sequential Immunometric Assays were used to determine blood concentrations of cortisol (Chiron Diagnostics Corporation, East Walpole, MA, USA), GH (Nichols Institute Diagnostics San Juan Capistrano, CA, USA) and ACTH (Euro/DPC, United Kingdom). Variances for the chemiluminescence assays were: cortisol: intra-assay $4.5 \%$, inter-assay $6.4 \%$; $\mathrm{GH}$ : intra-assay $4.0 \%$, inter-assay $9.2 \%$; and $\mathrm{ACTH}$ : intra-assay $5.9 \%$, inter-assay $3.9 \%$. Quantification of IGF-1 was performed using an Immunoradiometric Assay (IRMA) (DSL-5600 ACTIVE ${ }^{\text {TM }}$, DSL Deutschland $\mathrm{GmbH}$, Germany) with an intra-assay variance of $3.0 \%$ and an inter-assay of $1.5 \%$. A radioimmunoassay (RIA) was used for the determination of plasma TSH. The intra- and inter assay coefficients of variation were $2.8 \%$ and $4.9 \%$, respectively.

\section{Training}

To instigate a state of overreaching the subjects had to follow an extensive and intensified daily training program for two weeks. Before starting this two-week intensified training period, the normal training program was assessed over a period of two weeks (pre-intervention period). From day one of the pre-intervention period, until the end of the two-week intensified training period all athletes kept a training logbook in which they had to fill in their training time ( $\mathrm{min}$ ), and score the rate of perceived exertion (RPE) of each training on a 10-point Borg scale [7] with $1=$ very very low and $10=$ very very heavy. Training load, training strain and training monotony were subsequently calculated ac- cording to Foster et al. [17]. Based on the average daily training time over the pre-intervention period, a training schedule for the intensified training period was prepared. Since previous studies showed that a large increase in training volume, rather than training intensity, results in a state of overreaching or overtraining $[30,34]$, the training volume was doubled $(200 \%)$ during the intensified training period. However, the training intensity (based on their heart rate during the pre-intervention period and the maximal cycle ergometer test) was increased by $15 \%$, as well. Because in a study in horses, Bruin et al. [9] found that elimination of the recovery days during an intensified training period, induced signs of overtraining, the total amount of training hours was equally spread over all seven days of the week. In order to monitor training during the intensified training period, at least three training sessions per week were done in the laboratory. In the entire intensified training period, training intensity (and accordingly duration) of all training sessions was controlled by heart rate registration (Polar ${ }^{\circledR}$, Kempele, Finland). To ensure an appropriate recovery after the two-week intensified training period, the subjects were advised to lower the training volume during one week to $50 \%$ of their normal training load.

\section{Statistics \\ Cognitive speed test}

RTs less than $150 \mathrm{~ms}$ or in excess of $1.5 \mathrm{~s}$ were considered outliers and were excluded from data analyses; less than $0.3 \%$ of the RTs were removed using this criterion. Mean correct RTs and proportions of errors were calculated for each subject as a function of preparation condition, preparation interval, and time (pre vs. post test) A split-plot analyses of variance (ANOVA) [27] was performed on mean RTs and percentage errors with Intervention (control vs. intervention) as between-subject variable, and Preparation Condition (uncued, hand-cued, finger-cued, neithercued), Preparation Interval (100 and $2000 \mathrm{~ms}$ ), and Time (pre and post intervention) as within-subject variables. Whenever appropriate, the tests involving the within-subject factor(s) were adjusted for heterogeneity of variance and covariances using the Huynh-Feldt corrected significance values. Post-hoc analyses were carried out using Tukey's honestly significant procedure.

\section{Other parameters}

All data are presented as means \pm standard deviation (SD). To evaluate differences between the total pre and post intensified training hormone secretion, areas under the curve were measured during the SITT and CAPT, respectively. A Wilcoxon signed rank test for related pairs was applied to identify differences at each time point. All other test data were treated for significance with the Wilcoxon signed rank test for related pairs. Statistical significance was set at $\mathrm{p}<0.05$.

\section{Results}

All subjects successfully completed the two weeks' intensified training period. The average amount of training during the pretraining period was $420 \pm 204$ min per week. During the next two weeks (intensified training period) the subjects doubled the training volume to $872 \pm 295$ minutes per week $(825 \pm 279$ min and $939 \pm 378 \mathrm{~min}$ for wk 1 and wk 2, respectively). On a daily basis this means that the training session duration increased 
from an average of 84 min during the pre-intensified training period to an average of $117 \mathrm{~min}$ in week 1 and $188 \mathrm{~min}$ in week 2. This increase in training volume together with the $15 \%$ in training intensity, as based on heart rate, resulted in a significant increase in the individual training load $(\sim 100 \%$ increase, $\mathrm{p}<0.01)$, training strain $(\sim 220 \%$ increase, $\mathrm{p}<0.02)$, and training monotony $(\sim 85 \%$ increase, $\mathrm{p}<0.01)$. Body mass $(76.0 \pm 6.5$ vs. $75.8 \pm 6.0 \mathrm{~kg}$ ) and body fat $(13.3 \pm 2.5 \mathrm{vs.} 12.9 \pm 2.5 \%)$ was not significantly changed after the two weeks of intense training.

\section{Performance tests}

Intensifying the training load did not induce any significant changes in Wmax ( $4 \%$ increase, $\mathrm{p}=0.08$ ), $\mathrm{VO}_{2} \max$ ( $1 \%$ increase, $\mathrm{p}=0.86)$, HRmax ( $187.7 \pm 7.3$ and $181.1 \pm 9.4$, for pre- and post-intervention, respectively $[\mathrm{p}=0.13])$ and maximal lactate $(11.5 \pm 3.1$ and $11.2 \pm 2.4 \mathrm{mmol} \cdot \mathrm{l}^{-1}$, for pre- and post-intervention, respectively [n.s.]) attained during the incremental exercise test. The time to complete the pre-set amount of work was not significantly different ( $1 \%$ increase, $\mathrm{p}=0.84$ ) before and after the intensified training period.

\section{Psychological variables POMS}

The average mood state score is plotted in Fig. 3. Although not significant, the two weeks of increased training volume demonstrated a clear trend $(\mathrm{p}=0.06)$ towards an increased average mood score, reflecting an increase in worse mood state (35.8, 39.7 and 38.7 for baseline, week 1 and week 2 of the intensified training respectively). After analyzing the five sub scales of the POMS separately, none of them appeared to be significantly different compared to the baseline score. However, despite an absence of significant differences five of the subjects showed sustained increased mood and fatigue score during the intensified training period.

\section{Rating of perceived exertion (RPE)}

The mean RPE score increased significantly from $4.0 \pm 1.4$ in the pre-training period to $6.3 \pm 1.5$ in the first week of the intensified training. The mean RPE score decreased slightly during the second week of the intensified training period $(5.8 \pm 1.7)$ but remained significantly higher compared to the pre-intensified training period mean value (Fig. 4).

\section{Cognitive speed test}

The ANOVA revealed a highly significant effect for the factor preparation condition, $F(3,30)=37.16, \mathrm{p}<0.001$. The post - hoc analysis indicated faster RTs for all three cued conditions (Ms = 370, 394, and $403 \mathrm{~ms}$ for hand-, finger-, and neither-cued conditions, respectively) relative to the uncued condition $(M=420 \mathrm{~ms})$. This finding indicates that subjects engaged in selective preparation in the hand-, finger-, and neither-cued conditions. Furthermore, the three cued conditions differed among themselves (all $\mathrm{p}<0.05$ ), with the hand- and finger-cued conditions producing the shortest RTs and thus showing the largest preparation benefit.

The main effect of the preparation interval was also significant, $F$ $(1,10)=24.71, \mathrm{p}<0.001$, indicating shorter RTs in the $1000 \mathrm{~ms}$ than in the $100 \mathrm{~ms}$ preparation interval (375 and $419 \mathrm{~ms}$, respec-

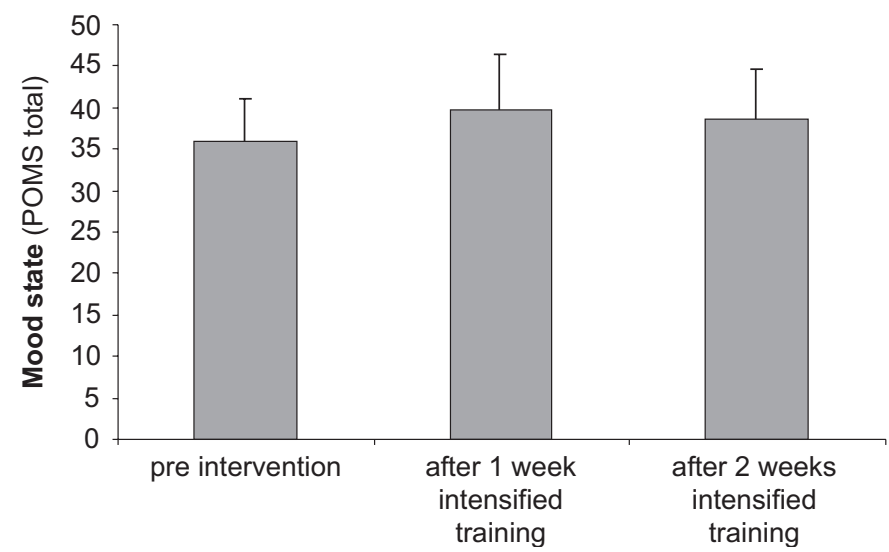

Fig. 3 The average mood score $( \pm S D$ ) on the shortened Profile of Mood State (POMS) before, during and directly after the two weeks of intensified training.

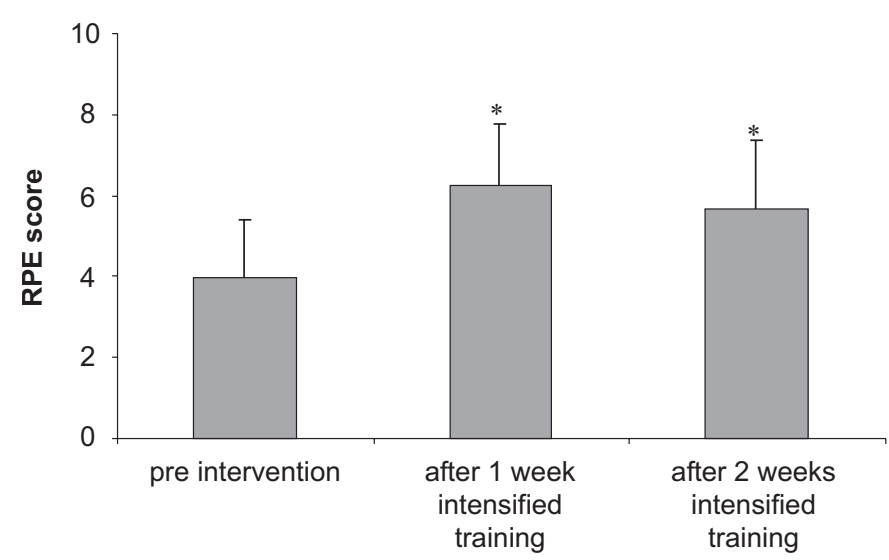

Fig. 4 The mean ratings ( \pm SD) of perceived exertion (RPE) before, during and directly after the two weeks of intensified training. ${ }^{*} \mathrm{p}<0.05$. Compared to pre-intervention.

tively). This finding shows that preparation takes time, with longer preparation intervals generating shorter RTs.

The significant main effect of time, $F(1,10)=3.99, \mathrm{p}<0.05$, indicated that, overall, RTs were shorter in the post-test than in the pre-test (390 vs. $404 \mathrm{~ms}$, respectively). Most likely, this effect is due to a learning or practice effect caused by performing the finger-precuing task two times (before and after the intensified training). Importantly, this learning effect was qualified by a significant three-way interaction involving the factors Intervention, Preparation Condition, and Time, $F(3,30)=3.14, \mathrm{p}<0.05$. This interaction indicated that the learning effect on RT was larger for the control group than for the intervention group but only for the most difficult conditions (i.e., the uncued and neither-cued conditions), with the hand- and finger-cued conditions showing similar learning effects in both groups (see Fig. 5). In other words, the negative effect of severe fatigue showed up as a failure to generate a learning effect in the uncued and neither-cued conditions.

\section{Errors}

Mean error rate was $4.6 \%$. Subjects in the control group tended to make more errors than subjects in the intervention group (5.6\% vs. $3.6 \%$, but this difference was not significant, $F(1,10)=2.31$, 


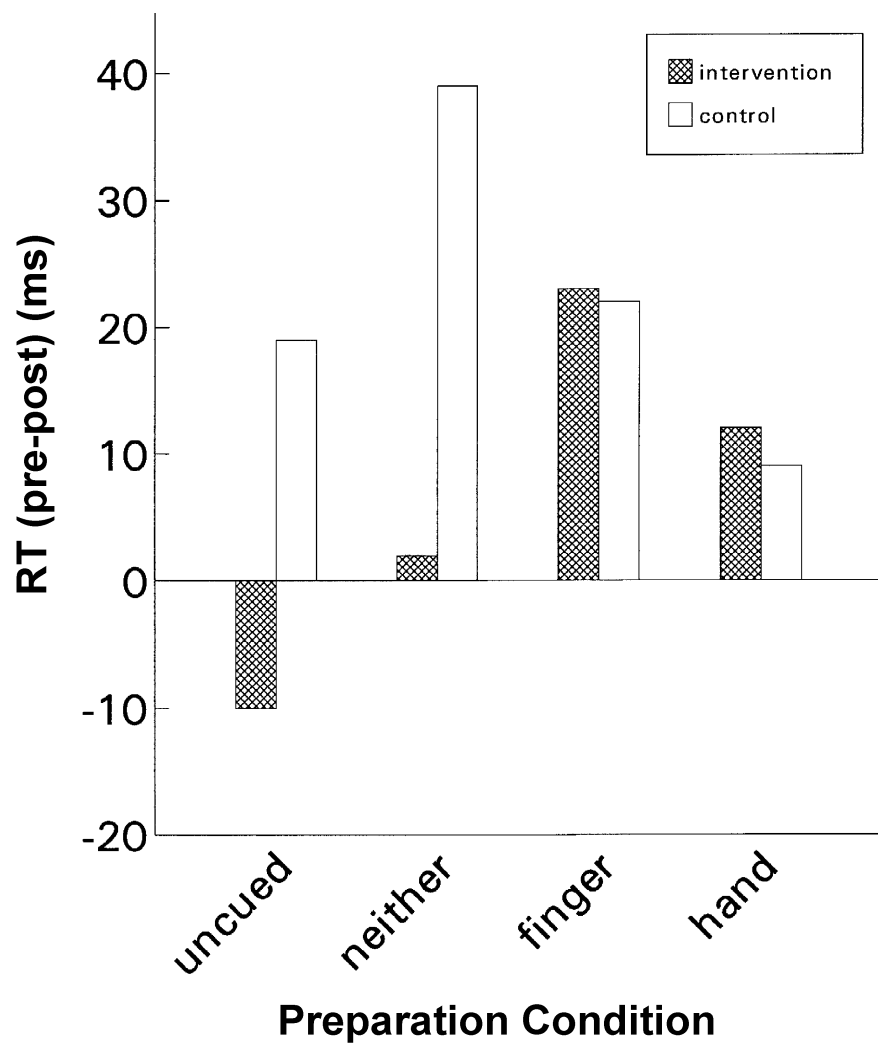

Fig. 5 The reaction time (RT) difference in the post-test relative to the pre-test for the control and intervention group as a function of preparation condition. Positive numbers denote shorter RTs in the post-test than in the pre-test (i.e., a learning effect); negative numbers denote longer RTs in the post-test than in the pre-test (i.e., an interference effect).

$\mathrm{p}>0.1$. The significant main effect of preparation condition, $F$ $(3,30)=4.64, \mathrm{p}<0.01$, indicated that subjects made most errors in the uncued and neither cued conditions (mean $=4.6 \%$ and $7.6 \%$, respectively), fewest in the hand-cued condition (mean = $1.0 \%$ ), and an intermediate number of errors in the finger-cued condition (mean $=3.2 \%$ ). Thus, generally, the conditions that showed the longest RTs also produced the most errors.

\section{Endocrine variables}

Maximal workload test

Resting and maximal values of cortisol and TSH tended to be lower whereas GH and ACTH showed a small increase after the intensified training period. However, these differences during rest and at maximal exercise were not significantly different from the pre-intervention tests. Furthermore the difference between rest and maximal values remained unaffected after the intensified training period as well.

\section{The short insulin tolerance test}

In all subjects the injection of insulin induced signs of hypoglycemia (sweating, drowsiness and hunger) and average nadir blood glucose levels were $2.1 \pm 0.2 \mathrm{mmol} \cdot l^{-1}, 20$ to $25 \mathrm{~min}$ after the insulin injection. No differences in plasma glucose concentrations at any time point could be observed between the pre and post test. The endocrine data from the insulin tolerance test are presented in Fig. 6. No significant modification in hormone secretion (summed concentrations over time) after two weeks of intensified training could be found.

\section{The combined anterior pituitary test}

Mean plasma concentrations of GH, TSH, ACTH and cortisol obtained during the CAPT are presented in Fig. 7. Summed cortisol concentrations over time were significantly $(p<0.05)$ decreased after the two weeks of intensified training. All other hormones tended to be decreased as well but this decrease was not significant.

\section{Hematological variables White blood cell profile}

An overview of the white blood cell variables is given in Table $\mathbf{1}$ All values for each subject were within the normal range. The total number of leucocytes and the sub-population of the leucocytes did not significantly change after the intensified training.

\section{Red blood cell profile}

All values for red blood cell variables were within the established normal ranges for men (Table 1). Only hemoglobin showed a significant $4.5 \%$ decrease $(\mathrm{p}<0.01)$ after the two weeks of training.
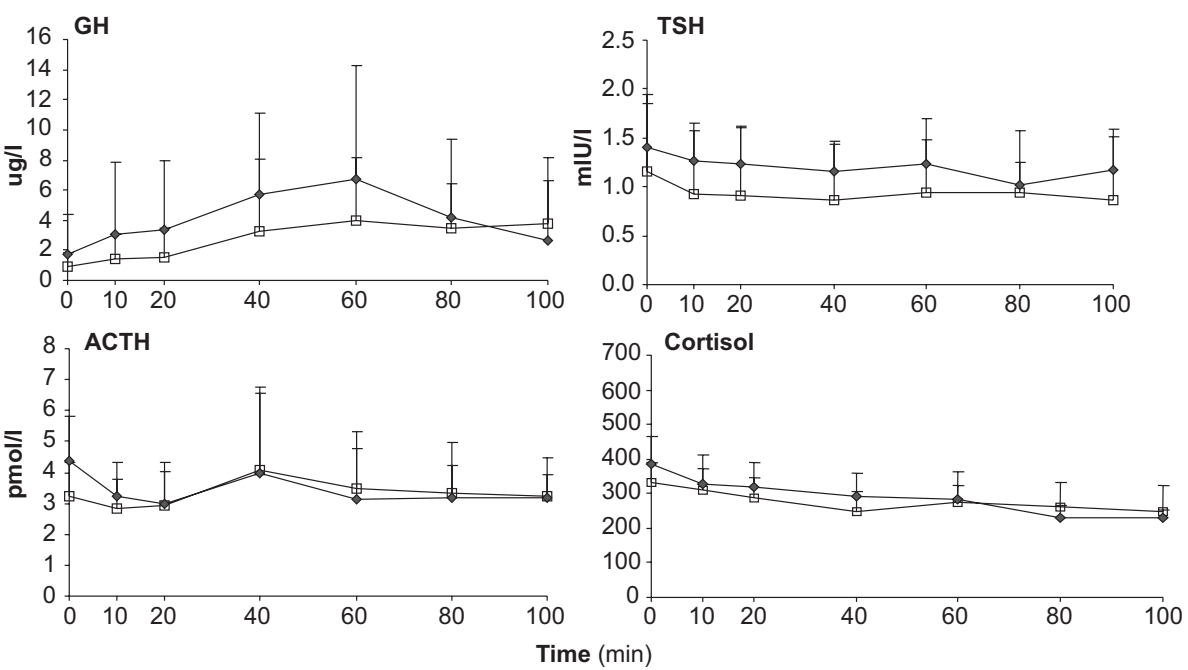

Fig. 6 Insulin Tolerance Test: dynamics of mean ( \pm SD) of growth hormone, TSH, ACTH and cortisol (nmol/l) before $(\diamond)$ and after $(\square)$ two weeks of intensified training.

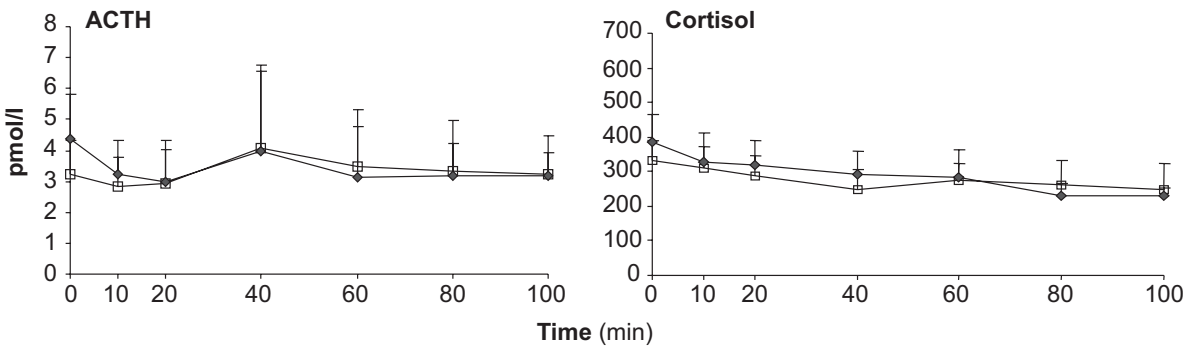



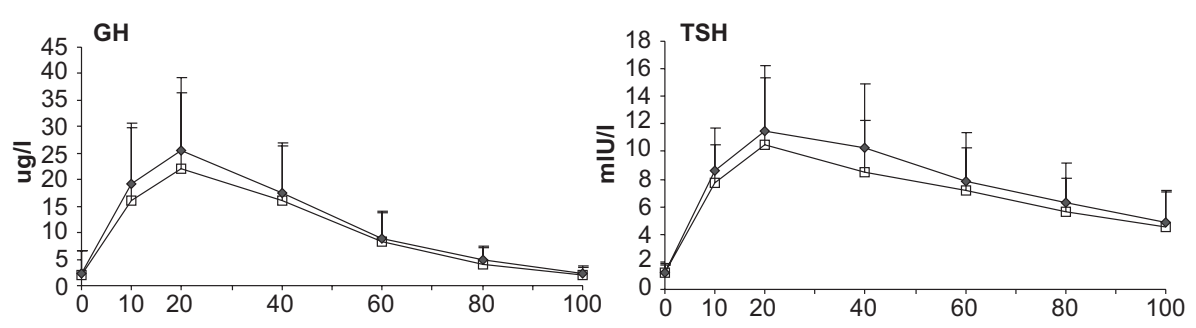

Fig. 7 Combined Anterior Pituitary Test: dynamics of mean ( \pm SD) of growth hormone, TSH, ACTH and cortisol (nmol/l) before $(\bullet)$ and after $(\square)$ two weeks of intensified training. The cortisol response was significantly reduced $(p<0.05)$ after the two weeks intensified training.
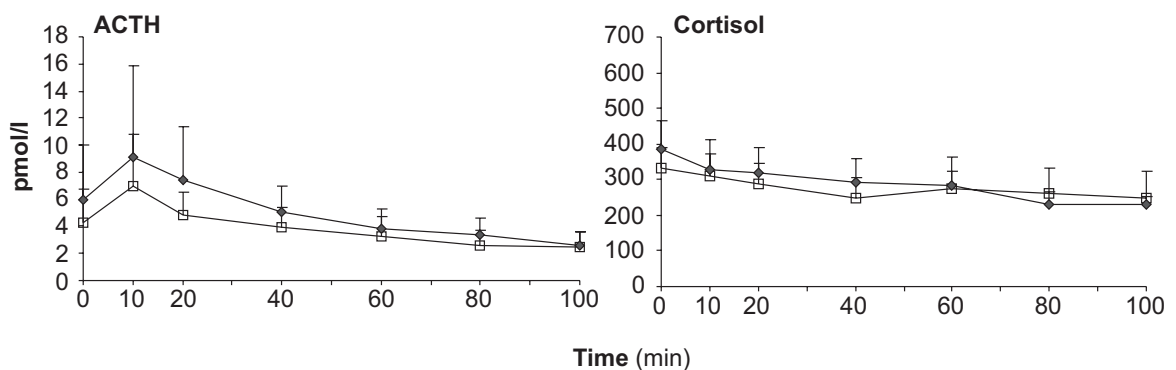

Although not significant, mean Hct (4.65\%), RBC (3\%) and MCV (3.5\%) showed a decrease after the intensified training period.

\section{Discussion}

The main purpose of the present study was to find potential early markers to identify overreaching and thus to prevent athletes reaching the state of the "overtraining syndrome". Since the symptomatology of this syndrome suggests the involvement of the higher brain centers, the hypothalamic-pituitary-adrenal, hypothalamic-pituitary-GH axis and peripheral organs, variables indicative for these systems have been measured. To induce a state of overreaching, the normal training volume of seven welltrained cyclists was doubled, and training intensity was increased by $15 \%$ as well. Although we were unable to show significant changes in physical performance, the intensified training period resulted in a significant increase in training load, strain and monotony. This suggests an imbalance between training, and recovery and indicates that the subjects indeed reached a state of overreaching, which is in agreement with the findings of Foster and co-workers [17]. Supportive for this finding was that after the two weeks of intensified training the exercise time of the time trial increased in five out of seven subjects, whereas RPE of the daily training sessions was significantly increased in all subjects during this period. In contrast, other performance indices such as the Wmax obtained from the incremental bicycle ergometer test did not decrease (as expected) during the two weeks of intensified training. The latter finding is in line with data from Bruin in horses [9]. Thus, an incremental performance test might not be sensitive enough to detect a small performance decrement during overreaching in its earliest stage. This is most likely explained by the normal day-to-day variability in performance obtained by incremental bicycle ergometer tests (i.e. approximately $5 \%$ ) [29], which is higher than the small differences in performance due to intensified training, at least in elite athletes.

To get more insight into exercise-induced changes in mood state and brain functioning, we used two different approaches. Firstly, we asked our subjects to fill in a shortened POMS questionnaire on a daily basis; secondly the subjects underwent a reaction task, which is indicative for cognitive function. No significant changes in the POMS global mood score or in one of the five sub-scales (tension, depression, anger, vigor and fatigue) for the whole group were found. Based on these results it might be argued that the POMS is not a strong early instrument for overreaching. This contrasts with findings of several (over)training studies where the POMS was mentioned as an efficient model to prevent overtraining in swimmers, runners and canoeists $[6,41,42,57]$. However, the results of the present study also indicate that the POMS can be useful in detection overreaching on an individual basis. This was based on the following findings: first of all there was a large difference in the inter-individual global POMS score. Six subjects showed an increase in the global mood score after one week of increased training load, reflecting a decrease in their mood state. This number of subjects remained the same in the second week of the intensified training but in three subjects the global mood score increased further, whereas in three others it decreased somewhat. Examination of the five sub-scales (tension, depression, anger, vigor and fatigue) did not reveal any significant change in any of the items. Despite a lack of significance in the mean score, six out of the seven subjects showed an increase in their anger score and a decrease in the vigor score already after one week of intensified training. Furthermore, four athletes had elevated fatigue scores. This resulted in a trend towards flattening of the classical iceberg profile normally found in athletes [40] caused by a decrease in the vigor score and an increase in the fatigue score (Fig. 8). In a previous study by Morgan et al., a strong dose-response relationship between training load, the ability to accomplish the training sessions and mood disturbance was found. The inverted iceberg profile (together with decrement in performance) was associated with an overtraining syndrome [41]. A possible explanation for this discrepancy between our study and others is the limited number of subjects in the present study and the wide scatter of the data, probably caused by the relatively short intensified training period. Furthermore, it is possible that the shortened version of the POMS is not as sensitive as the longer version as used by Raglin and colleagues [44-46]. 


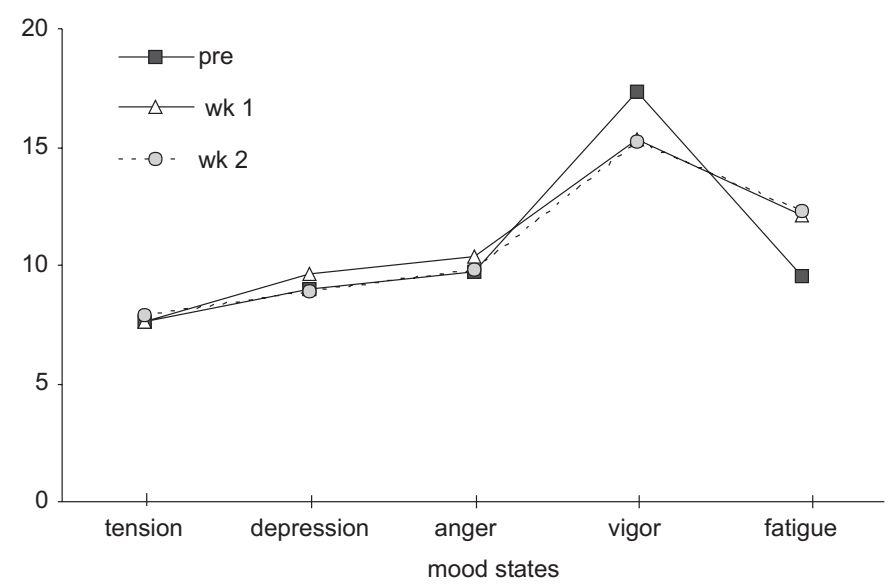

Fig. 8 Changes in the "iceberg profile" of the shortened Profile of Mood State (POMS) as a result of the increased training volume during the intervention period.

Further support for a negative effect of the intensified training period as used in the present study is provided by the significant increase in effort to accomplish each training session, which was reflected in a significant increase in training strain and training monotony. This finding is in line with two other studies in swimmers that found a progressive increase in RPE after increasing the training volume $[41,42]$, and corroborated the finding of Foster and co-workers who reported that an increase in training strain and training monotony is closely related to an increased incidence of an banal illnesses and injuries [17].

We used in the present investigation, to the best of our knowledge, for the first time a reaction time task, which is indicative of cognitive function, more specifically information processing of the brain $[1,38,52]$. The latter was operationalized by means of the finger-precuing reaction time task. This task is complex because it requires subjects to quickly process cue information, to select and prepare a subset of responses, and finally to select and execute a fast finger (i.e., button-press) response. Certain subsets of fingers are easier to prepare than others, with fingers on one hand (i.e., hand-cued) being the most easy to prepare and different fingers on different hands (i.e., neither-cued) the most difficult. Consistent with this fact, the present study showed that repeated performance of the finger-precuing task during the pretest and post-test sessions benefited the difficult neither-cued condition more than the relatively easy hand-cued condition. This was found for the control group. The overreached group, on the other hand, exhibited a different pattern. That is, whereas the overreached group did show a similar practice benefit for the hand-cued (and finger-cued) condition, as did the control group, it demonstrated no practice benefit for the more difficult neither-cued (and uncued) condition. From this result it appears that overreaching or severe fatigue has a negative impact on the more difficult conditions in the finger-precuing reaction time task, with the more easy conditions being insensitive to overreaching. Moreover, task complexity is an important mediating variable in the relationship between overreaching and brain functioning. This finding confirms and extends the results of a study by Tergau and co-workers [53]. Using noninvasive transcranial magnetic stimulation (TMS) in a double-pulse technique, these authors sought to assess fatigue of the motor cortex after exhaustive anaerobic strain (lifting exercise). They found that intra-cortical facilitation was markedly increased after exercise, indicating motor cortex fatigue. Thus, the findings of the study of Tergau and co-workers and the present one strongly suggest that central fatigue is the earliest manifestation of overreaching.

One of the aims of this study was to investigate whether large increases in training load, which may lead to overreaching, do affect the physiological neuro-endocrine response to standard stress tests. For this purpose, we used beside the exercise-induced endocrine response, the short insulin tolerance test (SITT) and the combined anterior pituitary test (CAPT). Insulin-induced hypoglycemia is considered as a heterologous stressor (in contrast to exercise, which is a homologous stressor). In healthy subjects an insulin-induced hypoglycemia activates hypothalamic neurons to stimulate the pituitary release of $\mathrm{ACTH}, \mathrm{GH}$ and TSH, and consequently plasma levels of these hormones will increase, as will the plasma cortisol level [50,51]. This hypoglycemic reaction is described to be rather robust [43]. Barron et al. introduced the SITT for the first time in four overtrained athletes [5]. In this study, four athletes with a likely overtraining syndrome were injected with $0.1 \mathrm{IU} \cdot \mathrm{kg}^{-1} \mathrm{BW}$ of insulin. A decreased responsiveness of the hypothalamic-pituitary system to hypoglycemic stress and consequently lowered plasma GH, ACTH and cortisol responses was demonstrated in these overtrained athletes. Since TRH and LHRH-induced TSH, PRL, LH and FSH responses were normal, it was concluded that hypothalamic or higher brain center rather than pituitary function caused the impaired response to an insulin-induced hypoglycemia.

In the present study no significant changes in any of the measured hormones were found. However, again we have to emphasize that the inter-individual variation was large. This was reported earlier by Viru and co-workers who found at least 4 different reaction patterns of plasma hormone responses during exercise in very well trained athletes [58]. However, it can also not be excluded that some of our subjects were overreached and others not. This notion is supported by the fact that some athletes responded on exercise and the CAPT after the intensified training period with a totally impaired GH secretion. Similar changes have not only been observed by other authors in overtrained cyclists [55], but also during depression [15]. Furthermore, the results from the CAPT demonstrated only a significantly lowered cortisol response over time. All other hormones showed no significant changes, albeit that there was a tendency for a lowered response. This indicates that intensified training induced a decreased responsiveness of the adrenal cortex. In an experimental overtraining study, Lehmann and co-workers found increased ACTH, GH, prolactin, LH and FSH plasma levels after an injection with releasing hormones [35]. Gastmann et al. observed a decreased pituitary ACTH response to corticotrophin-releasing hormone (CRH) in trained road cyclists at the end of their competitive season after two additional weeks of high-volume training [23].

An important finding of the present study is that an insulin dose of $0.1 \mathrm{IU} / \mathrm{kg}$ BW will almost inevitably lead to unacceptable severe hypoglycemia. In a pilot study preceding the present study, initially we started with the same dose as Barron et al. [5], but because all subjects ended with severe hypoglycemia, the dose 
was decreased to $0.04 \mathrm{IU} / \mathrm{kg}$ BW. Again we have to stress that in Barron's study only 4 athletes were included, whereas a lot of information about the training status of the athletes is lacking. We doubt whether the athletes in Barron's study were well trained, since it is well-known that endurance training increases insulin sensitivity considerably $[8,47]$.

Hematological changes are sometimes reported in overreached or overtrained athletes $[31,35]$ where others failed to find any changes [49]. In the present study significant differences in blood biochemical parameters after the intensified training period were limited to a reduction in $\mathrm{Hb}$. Hct, RBC and MCV tended to be lower as well, however all values were within the normal range. Red blood cell values at the lower limit of the normal range have often been reported in endurance athletes not suffering from overreaching or overtraining and are more likely a normal adaptation of endurance training $[11,24,48]$. Based on the results of the present study, it can be concluded that changes in the red blood cell profile are not specific to detect overtraining or overreaching and therefore not useable as an early marker for these situations. In overtrained athletes, susceptibility for infections and frequent illness is often reported [37]. Although somewhat speculative, there was a remarkably high number of subjects which suffered from flu-like symptoms after the intensified training period. However, in the present study no changes in the white blood cell profile were found after the intensified training period. This finding is in line with the findings of Fry et al. [19], Mackinnon et al. [37] and Gabriel et al. [22], but contrasts with findings of Baj et al. [4] and Lehmann et al. [36] who reported a decrease in the number of leucocytes after a period of strenuous training. Therefore it is concluded that changes in white blood cell distribution are not consistent and sensitive enough to detect overreaching at an early stage.

In conclusion, the novel finding of the present study is that cognitive function is the first and most sensitive parameter for detecting overreaching. It also shows that central fatigue precedes peripheral fatigue. Thus, the tests employed in the present study (reaction time values [indicative for cognitive functioning], combined with the POMS, [indicative for the mood state] and RPE scores [useful for calculating the subjective training load]) enables the athlete and his coach to prevent overreaching and overtraining. The present study once more showed that classical laboratory tests, including neuro-humoral tests are much less sensitive to detect overreaching in its early stage, which agrees with data from Urhausen and co-workers [56].

\section{Acknowledgement}

This research was supported by a grant from the Netherlands Olympic Committee and Netherlands Sports Federation (NOC and NSF).

The authors express their gratitude to Dr D. Sewell and Dr A. D. M. Kester for their valuable comments and to all the subjects for their tremendous amount of exercise.

\section{References}

${ }^{1}$ Adam JJ, Paas FG, Teeken JC, van Loon EM, van Boxtel MP, Houx PJ, Jolles J. Effects of age on performance in a finger-precuing task. J Exp Psychol Hum Percept Perform 1998; 24: 870-883

2 Akinmokun A, Selby PL, Ramaiya K, Alberti KG. The short insulin tolerance test for determination of insulin sensitivity: a comparison with the euglycaemic clamp. Diabet Med 1992; 9: 432-437

${ }^{3}$ Armstrong LE, VanHeest JL. The unknown mechanism of the overtraining syndrome: clues from depression and psychoneuroimmunology. Sports Med 2002; 32: 185-209

${ }^{4}$ Baj Z, Kantorski J, Majewska E, Zeman K, Pokoca L, Fornalczyk E, Tchorzewski H, Sulowska Z, Lewicki R. Immunological status of competitive cyclists before and after the training season. Int J Sports Med 1994; 15: $319-324$

${ }^{5}$ Barron GL, Noakes TD, Levi W, Smith C, Millar RP. Hypothalmic dysfunction in overtrained athletes. J Clin Endocrinol Metab 1985; 60: $803-806$

${ }^{6}$ Berglund B, Safstrom H. Psychological monitoring and modulation of training load of world-class canoeists. Med Sci Sports Exerc 1994; 26 : $1036-1040$

7 Borg GA. Psychophysical bases of perceived exertion. Med Sci Sports Exerc 1982; 14: 377-381

${ }^{8}$ Borghouts LB, Backx K, Mensink MF, Keizer HA. Effect of training intensity on insulin sensitivity as evaluated by insulin tolerance test. Eur J Appl Physiol 1999; 80: 461 - 466

${ }_{9}^{9}$ Bruin G, Kuipers H, Keizer HA, Vander Vusse GJ. Adaptation and overtraining in horses subjected to increasing training loads. J Appl Physiol 1994; 76: 1908 - 1913

${ }^{10}$ Chaouloff F. Physiopharmacological interactions between stress hormones and central serotonergic systems. Brain Res Brain Rev 1993; 18: $1-32$

${ }^{11}$ Clement DB, Asmundson RC, Medhurst CW. Hemoglobin values: comparative survey of the 1976 Canadian Olympic team. Can Med Assoc J 1977; 117: 614-616

12 Cluydts R, Visser P. Mood and sleep. I. Effects of the menstrual cycle. Waking Sleeping 1980; 4: 193 - 197

${ }^{13}$ Cluydts R, Visser P. Mood and sleep. II. Effects of aversive pre-sleep stimulation. Waking Sleeping 1980; 4: 199-203

14 Durnin JV, Womersley J. Body fat assessed from total body density and its estimation from skinfold thickness: measurements on 481 men and women aged from 16 to 72 years. Br J Nutr 1974; 32: 77-97

${ }^{15}$ Fiasche R, Fideleff HL, Moisezowicz J, Frieder P, Pagano SM, Holland M. Growth hormone neurosecretory dysfunction in major depressive illness. Psychoneuroendrinology 1995; 20: 727-733

${ }^{16}$ Fitzgerald L. Overtraining increases the susceptibility to infection. Int J Sports Med 1991; 12: 5-8

17 Foster C. Monitoring training in athletes with reference to overtraining syndrome. Med Sci Sports Exerc 1998; 30: 1164-1168

18 Fry AC, Kraemer WJ. Resistance exercise overtraining and overreaching. Neuroendocrine responses. Sports Med 1997; 23: 106-129

${ }^{19}$ Fry RW, Morton AR, Crawford GP, Keast D. Cell numbers and in vitro responses of leucocytes and lymphocyte subpopulations following maximal exercise and interval training sessions of different intensities. Eur J Appl Physiol 1992; 64: 218 - 227

${ }^{20}$ Fry RW, Morton AR, Keast D. Overtraining in athletes. An update. Sports Med 1991; 12: $32-65$

${ }^{21}$ Fry RW, Morton AR, Keast D. Periodisation and the prevention of overtraining. Can J Sport Sci 1992; 17: $241-248$

22 Gabriel HH, Urhausen A, Valet G, Heidelbach U, Kindermann W. Overtraining and immune system: a prospective longitudinal study in endurance athletes. Med Sci Sports Exerc 1998; 30: 1151 - 1157

23 Gastmann UAL, Lehmann MJ. Monitoring overload and regeneration in cyclists. In: Lehmann M, Foster C, Gastmann U, Keizer H, Steinacker JM (eds). Overload, Performance Incompetence and Regeneration in Sport. New York: Kluwer, Academic/Plenum Publishers, 1999

${ }^{24}$ Guglielmini C, Casoni I, Patracchini M, Manfredini F, Grazzi G, Ferrari $\mathrm{M}$, Conconi F. Reduction of $\mathrm{Hb}$ levels during the racing season in nonsideropenic professional cyclists. Int J Sports Med 1989; 10: 352 - 356

${ }^{25}$ Harro J, Rimm H, Harro M, Grauberg M, Karelson K, Viru AM. Association of depressiveness with blunted growth hormone response to maximal physical exercise in young healthy men. Psychoneuroendocrinology 1999; 24: $505-517$ 
${ }^{26}$ Jeukendrup A, Saris WH, Brouns F, Kester AD. A new validated endurance performance test. Med Sci Sports Exerc 1996; 28: 266-270

27 Keppel G. Design and Analysis: A Researcher's Handbook. 2nd rev. ed. New York: Englewood Cliffs, 1982: 669

${ }^{28}$ Kuipers H, Keizer HA. Overtraining in elite athletes. Review and directions for the future. Sports Med 1988; 6: 79-92

${ }^{29}$ Kuipers H, Verstappen FT, Keizer HA, Geurten P, van Kranenburg G. Variability of aerobic performance in the laboratory and its physiologic correlates. Int J Sports Med 1985; 6: 197-201

${ }^{30}$ Lehmann M, Baumgartl P, Wiesenack C, Seidel A, Baumann H, Fischer S, Spori U, Gendrisch G, Kaminski R, Keul J. Training - overtraining: Influence of a defined increase in training volume vs training intensity on performance, catecholamines and some metabolic parameters in experienced middle- and long-distance runners. Eur J Appl Physiol 1992; 64: 169-177

${ }^{31}$ Lehmann M, Dickhuth HH, Gendrisch G, Lazar W, Thum M, Kaminski R, Aramendi JF, Peterke E, Wieland W, Keul J. Training - overtraining. A prospective, experimental study with experienced middle- and long-distance runners. Int J Sports Med 1991; 12: 444-452

32 Lehmann M, Foster C, Gastmann U, Keizer H, Steinacker JM. Definition, types, symptoms, findings, underlying mechanisms, and frequency of overtraining and overtraining syndrome. In: Lehmann $\mathrm{M}$, Foster C, Gastmann U, Keizer H, Steinacker JM (eds). Overload, Performance Incompetence, and Regeneration in Sport. New York, Boston, Dordrecht, London, Moscow: Kluwer Academic/Plenum Publishers, 1999: $1-6$

${ }^{33}$ Lehmann M, Foster C, Keul J. Overtraining in endurance athletes: a brief review. Med Sci Sports Exerc 1993; 25: 854-862

${ }^{34}$ Lehmann M, Gastmann U, Petersen KG, Bachl N, Seidel A, Khalaf AN, Fischer S, Keul J. Training - overtraining: Performance, and hormone levels, after a defined increase in training volume versus intensity in experienced middle- and long-distance runners. Br J Sports Med 1992; 26: $233-242$

${ }^{35}$ Lehmann M, Knizia K, Gastmann U, Petersen KG, Khalaf AN, Bauer S, Kerp L, Keul J. Influence of 6-week, 6 days per week, training on pituitary function in recreational athletes. Br J Sports Med 1993; 27: 186 192

${ }^{36}$ Lehmann M, Mann H, Gastmann U, Keul J, Vetter D, Steinacker JM, Haussinger D. Unaccustomed high-mileage vs intensity trainingrelated changes in performance and serum amino acid levels. Int $\mathrm{J}$ Sports Med 1996; 17: $187-192$

37 Mackinnon LT, Hooper SL, Jones S, Gordon RD, Bachmann AW. Hormonal, immunological, and hematological responses to intensified training in elite swimmers. Med Sci Sports Exerc 1997; 29: 1637-1645

${ }^{38}$ Meyer DE, Osman AM, Irwin DE, Yantis S. Modern mental chronometry. Biol Psychol 1988; 26: 3-67

${ }^{39}$ Miller J. Discrete versus continuous stage models of human information processing: in search of partial output. J Exp Psychol Hum Percept Perform 1982; 8: 273-296

${ }^{40}$ Morgan WP. Affective beneficence of vigorous physical activity. Med Sci Sports Exerc 1985; 17: $94-100$
${ }^{41}$ Morgan WP, Brown DR, Raglin JS, O'Connor PJ, Ellickson KA. Psychological monitoring of overtraining and staleness. Br J Sports Med 1987; $21: 107-114$

42 Morgan WP, Costill DL, Flynn MG, Raglin JS, O'Connor PJ. Mood disturbance following increased training in swimmers. Med Sci Sports Exerc 1988; 20: $408-414$

43 Peino R, Leal A, Garcia-Mayor RV, Cordido F, Micic D, Kopeschaar H, Dieguez C, Casanueva FF. The use of growth hormone (GH) secretagogues in the diagnosis of GH deficiency in humans. Growth Horm IGF Res 1999; 9: 101 - 105

${ }^{44}$ Raglin JS, Morgan WP. Development of a scale for use in monitoring training-induced distress in athletes. Int J Sports Med 1994; 15: $84-$ 88

${ }^{45}$ Raglin JS, Morgan WP, Luchsinger AE. Mood and self-motivation in successful and unsuccessful female rowers. Med Sci Sports Exerc 1990; 22: 849-853

46 Raglin JS, Morgan WP, O'Connor PJ. Changes in mood states during training in female and male college swimmers. Int J Sports Med $1991 ; 12: 585-589$

47 Richter EA, Turcotte L, Hespel P, Kiens B. Metabolic responses to exercise. Effects of endurance training and implications for diabetes. Diabetes Care 1992; 15: 1767-1776

${ }^{48}$ Rietjens GJ, Kuipers H, Hartgens F, Keizer HA. Red blood cell profile of elite Olympic distance triathletes. A three-year follow-up. Int J Sports Med 2002; 23: 391 - 396

49 Rowbottom DG, Keast D, Goodman C, Morton AR. The haematological, biochemical and immunological profile of athletes suffering from the overtraining syndrome. Eur J Appl Physiol 1995; 70: 502 - 509

50 Sapolsky RM. Why stress is bad for your brain. Science 1996; 273: $749-750$

51 Sapolsky RM, Romero LM, Munck AU. How do glucocorticoids influence stress responses? Integrating permissive, suppressive, stimulatory, and preparative actions. Endocr Rev 2000; 21: 55-89

52 Schall JD. Neural correlates of decision processes: neural and mental chronometry. Curr Opin Neurobiol 2003; 13: 182 - 186

53 Tergau F, Geese R, Bauer A, Baur S, Paulus W, Reimers CD. Motor cortex fatigue in sports measured by transcranial magnetic double stimulation. Med Sci Sports Exerc 2000; 32: 1942 - 1948

54 Urhausen A, Gabriel H, Kindermann W. Blood hormones as markers of training stress and overtraining. Sports Med 1995; 20: 251 - 276

55 Urhausen A, Gabriel HH, Kindermann W. Impaired pituitary hormonal response to exhaustive exercise in overtrained endurance athletes. Med Sci Sports Exerc 1998; 30: 407-414

56 Urhausen A, Kindermann W. Diagnosis of overtraining: what tools do we have? Sports Med 2002; 32: 95-102

57 Verde T, Thomas S, Shephard RJ. Potential markers of heavy training in highly trained distance runners. Br J Sports Med 1992; 26: 167-175

58 Viru A, Karelson K, Smirnova T. Stability and variability in hormonal responses to prolonged exercise. Int J Sports Med 1992; 13: 230-235 